\title{
Brief Communication: Global reconstructions of glacier mass change during the 20th century are consistent
}

\author{
B. Marzeion ${ }^{1}$, P. W. Leclercq ${ }^{2}$, J. G. Cogley ${ }^{3}$, and A. H. Jarosch ${ }^{4}$ \\ ${ }^{1}$ Institute of Geography, University of Bremen, Bremen, Germany \\ ${ }^{2}$ Department of Geosciences, University of Oslo, Oslo, Norway \\ ${ }^{3}$ Department of Geography, Trent University, Peterborough, Canada \\ ${ }^{4}$ Institute of Earth Sciences, University of Iceland, Reykjavik, Iceland \\ Correspondence to: B. Marzeion (ben.marzeion@uni-bremen.de)
}

Received: 23 June 2015 - Published in The Cryosphere Discuss.: 20 July 2015

Revised: 10 November 2015 - Accepted: 30 November 2015 - Published: 17 December 2015

\begin{abstract}
Recent estimates of the contribution of glaciers to sea-level rise during the 20th century are strongly divergent. Advances in data availability have allowed revisions of some of these published estimates. Here we show that outside of Antarctica, the global estimates of glacier mass change obtained from glacier-length-based reconstructions and from a glacier model driven by gridded climate observations are now consistent with each other, and also with an estimate for the years 2003-2009 that is mostly based on remotely sensed data. This consistency is found throughout the entire common periods of the respective data sets. Inconsistencies of reconstructions and observations persist in estimates on regional scales.
\end{abstract}

\section{Introduction}

Reconstructions of past glacier mass change are of interest for several reasons: they help constrain the budget of past sea-level change (e.g., Gregory et al., 2013); they can contribute to the understanding of the magnitude of natural (internal and forced) climate variability; and they can contribute to isolating the anthropogenic signal in the climate system (Marzeion et al., 2014). Confidence in projections of future glacier change will also be increased if we can reproduce past glacier mass change. To do so, however, requires that we understand the past changes and their uncertainties. Estimating uncertainties that are robust in time and space is very hard for each individual reconstruction method. If the reconstruction is based on observations (both direct and geodetic mass change observations, as well as glacier length change observations, e.g., in Cogley, 2009; Leclercq et al., 2011), the uncertainty will be fundamentally governed by the sparse and probably unrepresentative sampling of observations from the entirety of the world's glaciers. In principle, it can be estimated whether the observed glaciers are representative of the global mean for periods where global observations exist (i.e., for the satellite period; but note that remotely sensed data, e.g., in Gardner et al., 2013, also have considerable uncertainty that can be hard to break down to the level of individual glaciers). The sampling, however, is not constant in time. We also cannot assume that a sample of glaciers representative of the global mean now has been so in the past or will be so in the future. If, in order to extend the period of observations, glacier length changes are used as a proxy for glacier volume change (Oerlemans et al., 2007; Leclercq et al., 2011), uncertainty in the relation between glacier length and volume is added to the sampling uncertainty.

Reconstructions based on modeling glacier change as a response to past observed (or modeled) climate change (e.g., Marzeion et al., 2012) carry some of the uncertainty from direct glacier mass change measurements (of individual glaciers; if all of the world's glaciers are modeled individually, the potential sampling bias is not carried on). More importantly, the errors of the glacier model can only be determined at times (typically, the second half of the 20th century) and in places where glacier mass change was measured (many observations from Europe, but few from heavily glacierized regions). The regions with above-average glaciological observations are also the regions with an above- 


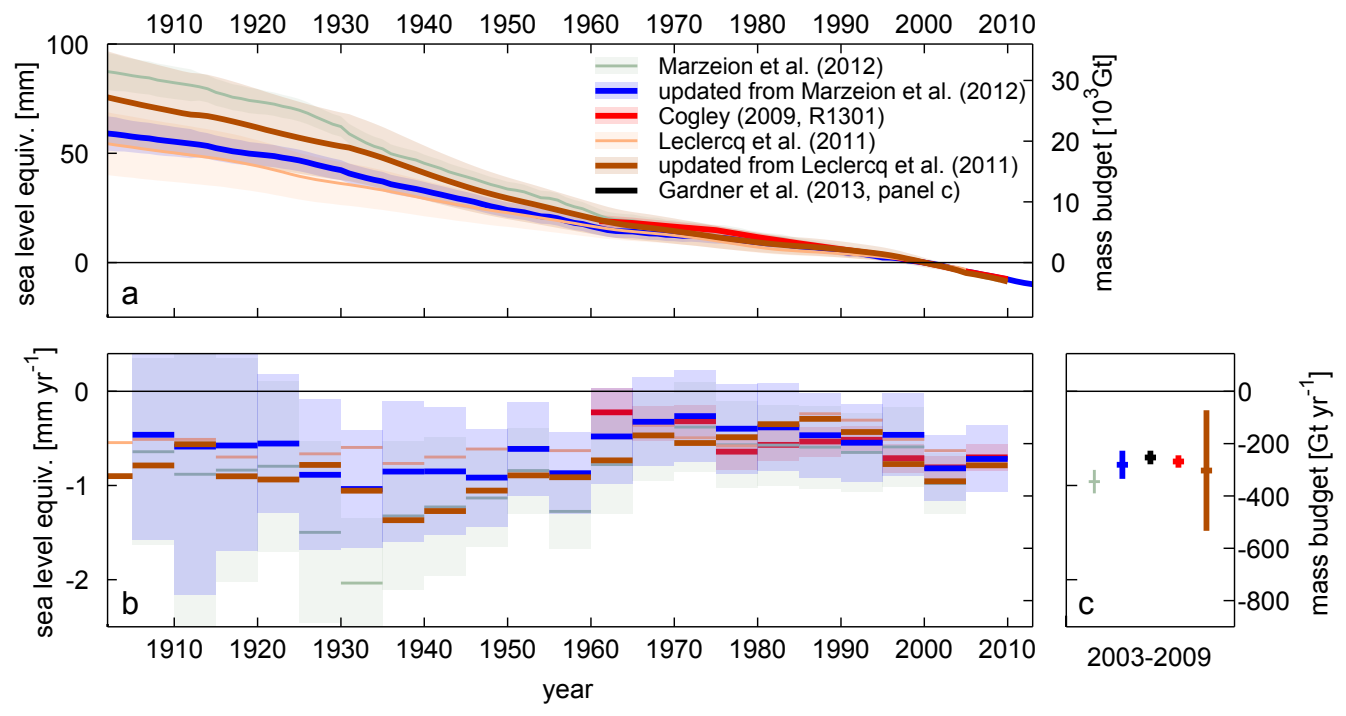

Figure 1. Globally integrated glacier mass change: (a) accumulated in time, relative to the year 2000; (b) 5-year mean values of mass change rates; (c) mean mass change rates during 2003 to 2009. Shading and error bars indicate $90 \%$ confidence interval. Note that all reconstructions exclude glaciers in the Antarctic periphery.

average meteorological measurement density. This implies that generally speaking, the model uncertainty is evaluated on glaciers where the forcing is based on atmospheric observations of above-average density and quality. Since there is no practical way to estimate the impact of spatial and temporal deterioration of climate reconstructions on glacier mass balance error, it is reasonable to assume that even model validation techniques that estimate uncertainty outside of the calibration sample (such as cross-validation) will underestimate the glacier model uncertainty. The same argument can be made regarding the quality of glacier outlines and hypsometries (Marzeion et al., 2012).

These considerations show that it is not surprising that reconstructions of glacier mass change tend to agree better within the second half of the 20th century than in earlier times (see Fig. 1). They also illustrate the benefit of a comparison of reconstructions based on multiple methods: the better the agreement of the different methods within their uncertainties, the higher the confidence in their robustness irrespective of the shortcomings of the individual uncertainty estimates.

Here we present revisions and updates of previously published estimates of past glacier mass change. We consider all glaciers outside of the Antarctic periphery, i.e., we include glaciers in the periphery of the Greenland ice sheet. We discuss the revisions and updates for each of the methods in Sect. 2 and show and discuss the results in Sect. 3.

\section{Revisions and updates of reconstructions}

\subsection{Direct and geodetic observations}

Cogley (2009) introduced a global mass balance compilation that included geodetic as well as direct measurements. The compilation, available at http://people.trentu.ca/ $\sim$ gcogley/glaciology/glglmbal.htm, has been updated several times. Gardner et al. (2013; see also Vaughan et al., 2013) found inconsistencies between regional and global mass changes obtained with measurements from release 1202 of the compilation and those obtained by orbital altimetry and gravimetry. Substantial additions of geodetic and especially regional-scale geodetic measurements were made in release 1203 and carried over to release 1301. Marzeion et al. (2014) relied on release 1301 and found less negative balances than those obtained with release 1202 . In particular, the inconsistency reported for 2003-2009 by Gardner et al. (2013) was somewhat reduced. It is further reduced in the present study by the exclusion of the Antarctic periphery, where measurements are few and in consequence the interpolation algorithm of Cogley (2009) yields unrealistically negative estimates of mass balance.

To illustrate the improvement of coverage in release 1301 relative to release 1202, over 1960-2012 the number of years of measured mass balance increased by $21 \%$ (from 14627 to 17673 balance years), with most of the increase accounted for by new geodetic measurements (increased by $28 \%$ ) rather than by new direct measurements (increased by $5 \%$ ).

Thus the density of temporal coverage is improved by the incorporation of geodetic mass balance measurements, 
which also improve spatial coverage. However, because most geodetic measurements are multi-annual, they tend to suppress interannual variability in regional and global estimates. This cost is offset to some extent by allowing explicitly for it in the calculation of uncertainties (as in Cogley, 2009) and also by calculating 5 -year rather than annual averages.

\subsection{Reconstruction based on glacier length changes}

Leclercq et al. (2011) extended the observation period of direct and geodetic observations (Cogley, 2009) with observations of glacier length changes to reconstruct the glacier mass change over the last 2 centuries. They used records of length change in 349 glaciers, distributed over 13 regions. To convert observed length change to global glacier mass change, the normalized glacier length changes were averaged to a global mean and then scaled to get a normalized global volume change. This normalized global volume change was translated into glacier mass change by calibration against the global glacier mass change over the period 1950-2005 based on Cogley (2009). Note that the results that we present here as Leclercq et al. (2011) differ from the published results, as we here consider only glaciers outside of the Antarctic periphery. The conversion of the results for global glacier mass change to glacier mass change excluding the Antarctic periphery is straightforward as the mass change in the Antarctic periphery in Leclercq et al. (2011) was based on upscaling the estimate for the rest of the world.

Here, we make use of additional data on both glacier length changes (Leclercq et al., 2012, 2014) and direct and geodetic mass changes (Cogley, 2009, release 1301). The reconstruction is now based on 456 glacier length records distributed over 15 regions. Compared to Leclercq et al. (2011), the number of records in the Arctic regions increased substantially, with over 90 new records in Novaya Zemlya, Alaska, and Greenland, such that the data set is more representative of the world's glaciers. Available length change data of glaciers in the Antarctic periphery are not considered here. The updates of the glacier length changes also made it possible to extend the reconstruction to 2010, instead of 2005, such that it now covers the period 1800-2010.

The new reconstruction presented here shows considerably more glacier mass change than the reconstruction of Leclercq et al. (2011) does. The difference can partly be ascribed to the updated glacier length change data set. Using the updated data set, the global normalized glacier change in the 1970 s and 1980s (i.e., within the calibration period) is smaller than that in Leclercq et al. (2011), while it is similar before 1960. This leads to an increase of $10 \mathrm{~mm}$ sea-level equivalent (SLE) in the reconstructed 20th-century glacier mass change. The cumulative mass change over the period 1950-2005 in the updated direct and geodetic observations is higher than in the earlier release used in Leclercq et al. (2011), which leads to an additional increase in the reconstructed glacier mass change of roughly $15 \mathrm{~mm}$ SLE. As dis- cussed more extensively by Leclercq et al. (2011), the reconstruction is strongly sensitive and directly proportional to the mass change derived from direct and geodetic observations, and uncertainties related to the calibration using the direct and geodetic observations are the main cause of uncertainty in the reconstruction.

\subsection{Modeled mass balances}

Marzeion et al. (2012) modeled the response of each glacier contained in version 1.0 of the Randolph Glacier Inventory (RGIv1.0; Arendt et al., 2014) based on gridded climate observations(Climatic Research Unit Time-Series (CRU CL 2.0) and Climatic Research Unit CLimatology (CRU TS 3.0); New et al., 2002; Mitchell and Jones, 2005). Terminus elevation, mean elevation, and maximum elevation of the glaciers were derived from version 2 of the ASTER (Advanced Spaceborne Thermal Emission and Reflection Radiometer) global digital elevation model (GDEMv2). Here, we update their reconstruction to RGIv4.0 and CRU TS 3.22 (Harris et al., 2014).

For the purpose of glacier modeling, the most significant difference between the CRU TS 3.0 and CRU TS 3.22 data sets is the extension of the covered time period from 19012009 to 1901-2013. While there are differences in the reconstructed glacier mass change also within the 20th century as a response to the updated climate forcing (globally, $4.6 \mathrm{~mm}$ SLE less mass loss), they are very small compared to the effects of updating from RGIv1.0 to RGIv4.0 and the associated changes to the glacier model.

Along the northern boundary of the coverage of the GDEMv2, we discovered elevation errors of several hundred meters, often covering several square kilometers (probably cloud tops misclassified as land surface), that impacted the terminus, mean, and maximum elevation calculations in Marzeion et al. (2012). These elevation errors led to overestimates of the elevation range of some glaciers, and therefore to overestimates of the solid precipitation, for which a lapse rate of $3 \% / 100 \mathrm{~m}$ elevation was assumed. This, through the calibration procedure, produced temperature sensitives of the affected glaciers that were too high. The region affected most strongly by these errors was the Russian Arctic, with some significant effects also in Svalbard and the northern periphery of Greenland. RGI v4.0 contains hypsometry data for almost all glaciers and avoids the GDEMv2 errors by considering other topographic data sets and by applying a spatial filter before calculating the hypsometric data. For some regions, there were considerable changes to the glacier outlines themselves, e.g., resulting in an increase in glacier area of $22 \%$ for North Asia and a decrease in glacier area of $53 \%$ in the Low Latitudes. For detailed information on the differences between RGIv1.0 and RGIv4.0, see Arendt et al. (2014). 
Table 1. Globally integrated glacier mass change reconstructions. Note that all reconstructions exclude glaciers in the Antarctic periphery.

\begin{tabular}{lcccc}
\hline & \multicolumn{2}{c}{ Mass change (mm SLE) } & Mass change rate (mm SLEyr ${ }^{-1}$ ) \\
\cline { 2 - 3 } & $1961-2005$ & $1902-2005$ & $2003-2009$ \\
\hline Leclercq et al. (2011) & $19.2 \pm 4.9$ & $57.5 \pm 14.4$ & - \\
Marzeion et al. (2012) & $26.4 \pm 3.1$ & $92.3 \pm 7.7$ & $0.96 \pm 0.12$ \\
\hline Gardner et al. (2013) & - & - & $0.70 \pm 0.07$ \\
Cogley (2009, R1301) & $23.0 \pm 2.8$ & - & $0.75 \pm 0.07$ \\
Updated from Leclercq et al. (2011) & $24.3 \pm 7.1$ & $80.4 \pm 21.1$ & $0.87 \pm 0.64$ \\
Updated from Marzeion et al. (2012) & $19.9 \pm 3.4$ & $63.2 \pm 7.9$ & $0.78 \pm 0.15$ \\
\hline
\end{tabular}

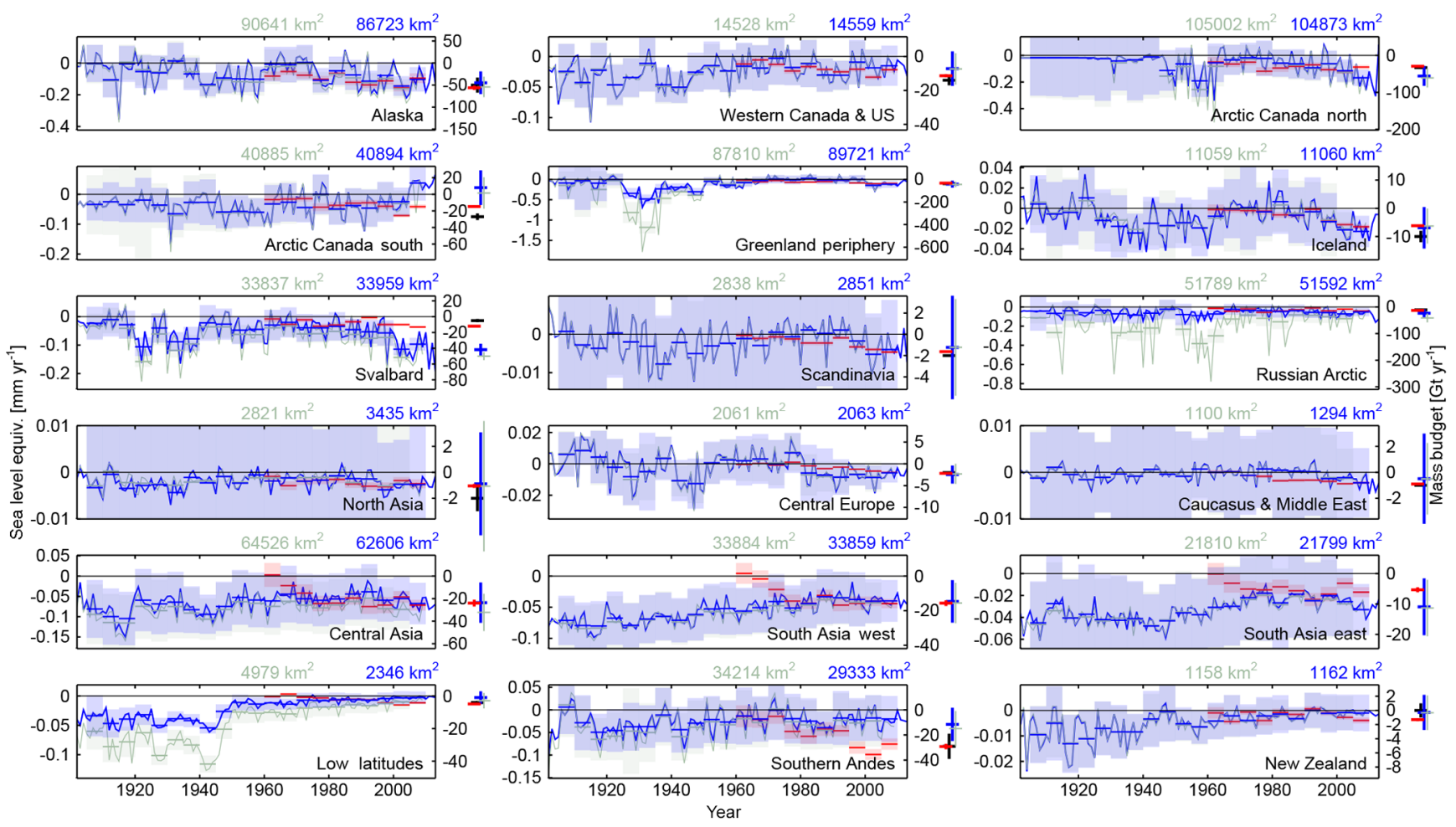

Figure 2. Regional glacier mass change rates; colors as in Fig. 1. Shading indicates the $90 \%$ confidence interval of the 5-year means. Numbers given at the top of each panel indicate glacier area in RGIv1.0 (green) and RGIv4.0 (blue). Crosses on the right of each panel give mass change rate and $90 \%$ confidence interval during 2003-2009.

\section{Results}

\subsection{Global scale}

The lowered temperature sensitivities of the glaciers affected by the elevation error in Marzeion et al. (2012) lead to lower estimates of global glacier mass change in the reconstruction based on climate observations (Fig. 1a and Table 1). The differences are greatest in the first half of the 20th century. This is a result of the negative feedback between terminus elevation and mass balance, which becomes positive when going backwards in time: mass loss in 1 year implies a lower terminus in the preceding year, which leads to a more negative mass balance in the preceding year ${ }^{1}$. This feedback was further erroneously enhanced in Marzeion et al. (2012) through the overestimated elevation ranges: for reconstructions, systematic mass balance errors were amplified further back in time. In forward model runs, the errors are accordingly dampened, which explains why the corrected elevation ranges affect the projections of Marzeion et al. (2012) far less. The resulting differences are negligible compared to the dominant uncertainty, which for projections is the spread of

\footnotetext{
${ }^{1}$ Note that in reality this feedback is to some extent balanced by the mass-balance-surface-elevation feedback. This feedback, however, is not included in the model.
} 
the climate model ensemble used to force the glacier model (not shown).

The revised mass change reconstruction based on glacier length change shows higher mass loss during the 20th century than in Leclercq et al. (2011), leading to an agreement (within their respective uncertainties) of the reconstructions based on glacier length change and climate observations throughout the entire length of their overlapping periods. There is also agreement of the 5-year, global mean rates of glacier mass change (Fig. 1b) of the revised reconstructions and for the 2003-2009 period (Fig. 1c), for which altimetric and gravimetric data give relatively tight uncertainty constraints for several strongly glaciated regions (Gardner et al., 2013). Even though the uncertainty ranges are still relatively large, this result indicates that the different reconstruction methods are converging as more and higher-quality data are becoming available. This increases confidence in the methods' viability.

Strictly speaking, the three reconstructions considered here are not independent over the entire time because (i) the glacier-length-based estimate of Leclercq et al. (2011) is calibrated globally using the direct and geodetic mass change observations of Cogley (2009) and (ii) the estimate based on climate observations of Marzeion et al. (2012) is calibrated using direct mass change observations of 255 glaciers that also enter Cogley (2009). The practical limitations caused by this dependence are minor, as can be seen in Fig. 2: even though the validation in Marzeion et al. (2012) does not indicate a model bias on those glaciers that enter Cogley (2009), the regional mean estimates of the two methods are strongly divergent in some regions, which would not be possible if the dependence was strong.

\subsection{Regional scale}

While the agreement of the reconstructions on the global scale is clearly improved, the comparison of the climate observation-based reconstruction with the results of Gardner et al. (2013) still shows considerable differences for some of the regions. In regions where the spatial and temporal density of glacier observations is high (e.g., Western Canada and USA, Scandinavia, Central Europe, the Caucasus and the Middle East - regions are given using the official RGI names; see Gardner et al., 2013), there is good agreement between both the old and the revised model-based reconstructions and observations. This reflects the abundance and generally high quality of glaciological and meteorological data in these regions.

The greatest improvement in the agreement between observations and reconstruction can be found in the Russian Arctic. There are also considerable changes to the reconstruction in Greenland and Svalbard (in these cases, as with the Russian Arctic, due to the corrected elevation errors) and in the Low Latitudes (due to the strongly reduced glacier area in RGIv4.0). However, since the changes mostly affect the period prior to the estimate of Gardner et al. (2013), it is unclear whether these changes improve the regional estimate (we can only conclude that the total sum of regional changes improved, based on the better agreement on a global scale described in Sect. 3.1). These regions, especially Greenland (Fig. 2), accounted for much of the rapid mass loss reconstructed for 1930-1935 by Marzeion et al. (2012), and this excursion is now more subdued.

In all other regions, the effects of the revision are negligible. The strong disagreement during the 2003-2009 period, particularly in Svalbard and the Canadian Arctic, is not resolved and is even increased in the Southern Andes. While the reason for this disagreement is not obvious, we see at least four potential explanations.

(i) The model-based reconstruction is motivated by the generally better availability and quality of meteorological observations compared to glaciological observations, particularly in the early period of the reconstruction. During the most recent years, it is possible that the station-based meteorological observations reflect the spatial and temporal atmospheric variability less well than remotely sensed data of glaciers.

(ii) The glacier model's calibration routine (Marzeion et al., 2012) relies on the assumption that the sampling of direct glacier observations is dense enough to reflect the spatial scale of climate anomaly patterns. In sparsely sampled regions, and in regions with small-scale variability, this assumption will limit the success of glacier mass balance reconstructions.

(iii) Calving is not explicitly considered in the model but is responsible for a considerable fraction of the mass budget of many high-latitude glaciers. The implicit treatment of calving will limit the model's ability to reflect the full temporal variability of the glacier mass balance and in particular the partial decoupling of glacier mass change and climate forcing that may occur for calving glaciers.

(iv) The sampling of glacier observations may not be representative of entire regions if based on direct observations of individual glaciers and may be affected by methodological uncertainties (e.g., in the conversion of volume change to mass change for geodetic estimates or by leakage of mass change from other components of the Earth system and/or other regions for gravimetric data).

\section{Conclusions}

Additional glacier length data (Leclercq et al., 2012, 2014), updates of the RGI (Arendt et al., 2014) and associated corrections of errors in glacier elevation data, additional more extensive geodetic measurements of glacier mass change, 
and extensions of gridded climate observations (Harris et al., 2014) encouraged us to revise reconstructions of 20thcentury glacier mass change. These revisions lead to results that are consistent with each other on the global scale and on all common time scales. Inconsistencies remain in the recent past (2003-2009) in some regions between our reconstructions and a consensus estimate that relies strongly on altimetric and gravimetric data (Gardner et al., 2013), particularly in Arctic regions.

The newly achieved consistency between the two reconstructions may simply mean that they are consistently wrong, such that future improvements in observations of glacier length change, glacier mass change, glacier geometries included in the RGI, as well as model formulation may lead to different estimates of 20th-century glacier mass change. However, the strongest evidence for this argument, namely the discrepancy with altimetric and gravimetric estimates during 2003-2009, is now less strong, as seen in Fig. 1c and Table 1.

\section{The Supplement related to this article is available online at doi:10.5194/tc-9-2399-2015-supplement.}

Acknowledgements. This work was funded by the Austrian Science Fund (FWF): P22443-N21 and P25362-N26, and supported by the Austrian Ministry of Science (BMWF) as part of the UniInfrastrukturprogramm of the Focal Point Scientific Computing at the University of Innsbruck. P. W. Leclercq acknowledges funding by the European Research Council under the European Union's Seventh Framework Programme (FP/2007-2013)/ERC grant agreement no. 320816. We thank two anonymous reviewers for their comments, which helped to improve the manuscript.

Edited by: G. Hilmar Gudmundsson

\section{References}

Arendt, A., Bliss, A., Bolch, T., et al.: Randolph Glacier Inventory A Dataset of Global Glacier Outlines: Version 4.0, Global Land Ice Measurements from Space, Boulder Colorado, USA, Digital Media, 2014.

Cogley, J. G.: Geodetic and direct mass-balance measurements: comparison and joint analysis, Ann. Glaciol., 50, 96-100, doi:10.3189/172756409787769744, 2009.

Gardner, A. S., Moholdt, G., Cogley, J. G., Wouters, B., Arendt, A. A., Wahr, J., Berthier, E., Hock, R., Pfeffer, W. T., Kaser, G., Ligtenberg, S. R. M., Bolch, T., Sharp, M. J., Hagen, J. O., van den Broeke, M. R., and Paul, F.: A reconciled estimate of glacier contributions to sea level rise: 2003 to 2009 , Science, 340, 852-857, doi:10.1126/science.1234532, 2013.
Gregory, J. M., White, N. J., Church, J. A., Bierkens, M. F. P., Box, J. E., van den Broeke, M. R., Cogley, J. G., Fettweis, X., Hanna, E., Huybrechts, P., Konikow, L. F., Leclercq, P. W., Marzeion, B., Oerlemans, J., Tamisiea, M. E., Wada, Y., Wake, L. M., and van de Wal, R. S.: Twentieth-century globalmean sea-level rise: is the whole greater than the sum of the parts?, J. Climate, 26, 4476-4499, doi:10.1175/JCLI-D-12$00319.1,2013$.

Harris, I., Jones, P., Osborn, T., and Lister, D.: Updated high-resolution grids of monthly climatic observations the CRU TS3.10 Dataset, Int. J. Climatol., 34, 623-642, doi:10.1002/joc.3711, 2014.

Leclercq, P. W., Oerlemans, J., and Cogley, J. G.: Estimating the glacier contribution to sea-level rise for the period 1800-2005, Surv. Geophys., 32, 519-535, doi:10.1007/s10712-011-9121-7, 2011.

Leclercq, P. W., Weidick, A., Paul, F., Bolch, T., Citterio, M., and Oerlemans, J.: Brief communication "Historical glacier length changes in West Greenland", The Cryosphere, 6, 1339-1343, doi:10.5194/tc-6-1339-2012, 2012.

Leclercq, P. W., Oerlemans, J., Basagic, H. J., Bushueva, I., Cook, A. J., and Le Bris, R.: A data set of worldwide glacier length fluctuations, The Cryosphere, 8, 659-672, doi:10.5194/tc8-659-2014, 2014.

Marzeion, B., Jarosch, A. H., and Hofer, M.: Past and future sealevel change from the surface mass balance of glaciers, The Cryosphere, 6, 1295-1322, doi:10.5194/tc-6-1295-2012, 2012.

Marzeion, B., Cogley, J. G., Richter, K., and Parkes, D.: Attribution of global glacier mass loss to anthropogenic and natural causes, Science, 345, 919-921, doi:10.1126/science.1254702, 2014.

Mitchell, T. D. and Jones, P. D.: An improved method of constructing a database of monthly climate observations and associated high-resolution grids, Int. J. Climatol., 25, 693-712, doi:10.1002/joc.1181, 2005.

New, M., Lister, D., Hulme, M., and Makin, I.: A high-resolution data set of surface climate over global land areas, Clim. Res., 21, 1-25, doi:10.3354/cr021001, 2002.

Oerlemans, J., Dyurgerov, M., and van de Wal, R. S. W.: Reconstructing the glacier contribution to sea-level rise back to 1850 , The Cryosphere, 1, 59-65, doi:10.5194/tc-1-59-2007, 2007.

Vaughan, D., Comiso, J., Allison, I., Carrasco, J., Kaser, G., Kwok, R., Mote, P., Murray, T., Paul, F., Ren, J., Rignot, E., Solomina, O., Steffen, K., and Zhang, T.: Observations: cryosphere, in: Climate Change 2013: the Physical Science Basis. Contribution of Working Group I to the Fifth Assessment Report of the Intergovernmental Panel on Climate Change, edited by: Stocker, T., Qin, D., Plattner, G.-K., Tignor, M., Allen, S., Boschung, J., Nauels, A., Xia, Y., Bex, V., and Midgley, P., Cambridge University Press, Cambridge, UK, New York, NY, USA, 317-382, 2013. 